\title{
HUMAN CUTANEOUS ANTHRAX - A CASE REPORT
}

T his report describes the circumstances and clinical findings of a case of human cutaneous anthrax, and discusses the public health implications.

Anthrax is a zoonosis that was endemic in Europe before the introduction of an effective animal vaccine. Koch, in the late 1800 s, demonstrated the bacterial aetiology of anthrax, the first disease to which a bacterial cause was ascribed. ${ }^{1}$

Human anthrax is still a problem in many regions of the world, ${ }^{2,3,4,5}$ although in developed countries it is uncommon. In NSW there have been only two reported cases of human anthrax since 1982.

Anthrax is caused by the Bacillus anthracis, a sporeforming, gram-positive organism. The spores are extremely resistant to adverse environmental conditions, ${ }^{6}$ surviving high temperatures and drying, and can remain dormant but potentially infective for more than 20 years. ${ }^{8}$ Pathophysiologic effects in infected animals or humans are due to toxins produced by the organism?

The main reservoirs of infection are domestic herbivores such as sheep, cattle and goats.

Human infection comes from direct contact with contaminated skins or carcasses, inhalation of spores from contaminated animal products such as wool fibres or bone meal, or from eating infected meat?

The index case, a 35-year-old male, initially presented to a general practitioner with a number of vesicular lesions on his hands which the patient himself suspected to be anthrax. The patient was otherwise well and was given oral penicillin. In the following 24 hours, the man became systemically unwell and was admitted to a metropolitan hospital for intravenous penicillin therapy.

The vesicular lesions developed black necrotic lesions typical of cutaneous anthrax. B. anthracis was cultured from the swabs taken by the GP. The organism was not found in the patient's blood or in the lesions.

Three days before going to the GP, the patient, with two others, had been slaughtering sheep on a property in western NSW. There was no evidence of anthrax on that property, although it was known to be present in neighbouring properties.

The carcasses were to be used as feed for animals in a Sydney wildlife park. Eight other staff members of the park had direct contact with the carcasses.

Anthrax is common among stock in NSW, but human anthrax is uncommon. It is potentially fatal, especially if accompanied by septicaemia and severe toxaemia. Cutaneous anthrax comprises $90-95$ per cent of all human anthrax, and has a case fatality rate of $10-20$ per cent if untreated. ${ }^{9}$
For public health, it is important that all human contacts be treated appropriately, and that contaminated materials be disposed of in a manner that eliminates further human or animal exposure.

All definite contacts, and many others at the wildlife park who were not at risk, were treated with oral penicillin for at least five days. The treatment of noncontacts was unnecessary but deemed justifiable in view of the high level of anxiety, and the relatively low cost of treatment.

It is recommended that contaminated materials be incinerated or disinfected, and that infected carcasses be covered with anhydrous calcium oxide (quicklime) during deep burial. Some of the potentially contaminated materials were burnt, while others were disinfected with 5 per cent formalin solution.

The contaminated carcasses were buried, without any quicklime, at a local waste depot before involvement of the Public Health Unit. Though not the most appropriate site for disposal, it was the most accessible at the time. Fortunately, the buried carcasses are unlikely to be disturbed, since as normally is the case, the waste depot would be designated 'unhealthy building land' under the Public Health Act.

There was the potential for many more cases of human anthrax and it was fortunate that only one case was confirmed. In this case the diagnosis was confirmed by bacterial culture. If microbiological confirmation is not possible, or in epidemiological investigations, serological diagnosis is both sensitive and specific., ${ }^{4,5}$

Eradication of human anthrax depends primarily on the ability to control it in domestic animals by effective surveillance and vaccination programs. Vaccination for humans is not available in Australia, so preventive measures should be emphasised to high-risk groups.

\section{Bin Jalaludin \\ Research officer \\ Elizabeth Sullivan \\ Acting director \\ Western Sector Public Health Unit}

1. The Story of Vaccination, 1974, Sarah R Riedman, Bailey Brothers and Swinfen, United Kingdom.

a.

2. Roberts CJ, Chambers PG, An outbreak of ant
tribal trust lands, Cent A $f J M e d$ 1975;21:73-76.

3. Heyworth B, Ropp ME, Voos UG, et al, Ant

epidemiological study, $B$ Med $J 1975 ; 4: 79-82$.

4. Sirisanthana T, Nelson KE, Ezzell JW, et al, Serological studies of

patients with cutaneous and oral-oropharyngeal anthrax from Northern Thailand, AM J Trop Med Hyg 1988;39:475-581.

5. Harrison LH, Ezzell JW, Abshire TG, et al, Evaluation of serologic tests for diagnosis of anthrax after an outbreak of cutaneous anthrax in Paraguay, J Infect Dis 1989;160:706-710.

6. Ditz W, Kohout-Dutz E, Anthrax, Int J Derm 1981;20:203-206.

7. Yorston D, Foster A, Cutaneous anthrax leading to corneal scarring from cicatricial ectropion, B J Opthal 1989;73:809-811.

8. Dogaray M, Bakir M, Dokmetas I, A case of cutaneous anthrax with toxaemic shock, B J Derm 1987;117:659-662.

9. Control of Communicable Diseases in Man, Editor: Bennenson AS,

15th ed, 1990, American Public Health Association, Washington. 